\title{
Experiências escolares, aprendizagem e cultura: produção do sujeito surdo no cenário da escola contemporânea
}

\author{
School experiences, learning and culture: production of the deaf subject in \\ the contemporary school setting
}

Experiencias escolares, aprendizaje y cultura: producción del sujeto sordo en el escenario de la escuela contemporânea

Márcia Lise Lunardi-Lazzarin

Professora doutora na Universidade Federal de Santa Maria, Santa Maria, Rio Grande do Sul, Brasil. lunazza@gmail.com

ORCID - https://orcid.org/0000-0003-4831-129X

\section{Anie Pereira Goularte Gomes}

Doutoranda na Universidade Federal de Santa Maria, Santa Maria, Rio Grande do Sul, Brasil.

anie.ufsm@gmail.com

ORCID - https://orcid.org/0000-0001-8802-758X

Camila Righi Medeiros Camillo

Doutoranda na Universidade Federal de Santa Maria, Santa Maria, Rio Grande do Sul, Brasil. camilacamillo1@yahoo.com.br

ORCID - https://orcid.org/0000-0003-1655-1125

Recebido em 22 de novembro 2019

Aprovado em 4 de junho de 2020

Publicado em 8 de julho de 2020

\section{RESUMO}

O presente artigo tem como objetivo compreender a articulação entre os conceitos de cultura e de aprendizagem como condição de possibilidade para pensar a produção do sujeito surdo no cenário da escola contemporânea. Para dar conta de tal problemática, a análise empreendida tomará como base os dados de uma pesquisa realizada em 13 escolas específicas de surdos do Rio Grande do Sul. A partir desse empreendimento analítico, que coloca em operação dois possíveis conceitos-ferramenta - subjetivação e dispositivo pedagógico -, selecionamos 20 entrevistas com alunos surdos e 4 entrevistas com professores, em um universo de 156 sujeitos. Com base nas narrativas, consideramos as singularidades e recorrências discursivas que tangenciam as noções de cultura e de aprendizagem na escolarização das pessoas surdas. Sobre esse amálgama de verdades instituídas é que tensionamos o que vem sendo produzido sobre o ser surdo no contexto da educação bilíngue, inferindo e imprimindo desejos de ser, aprender e viver.

Palavras-chave: Cultura surda; aprendizagem; experiências escolares.

\section{ABSTRACT}

The present paper aims to understand the articulation between the concepts of culture and learning as a condition of possibility to think about the production of the deaf subject in the contemporary school setting. To address this issue, the analysis was grounded on data from a research carried out in 13 schools for the deaf in Rio Grande do Sul. From this analysis, 
which put in operation two possible key concepts - subjectification and pedagogical device - we selected 20 interviews with deaf students and 4 interviews with teachers from a group of 156 subjects. Based on the narratives, we approached the singularities and discursive recurrences that reach the notions of culture and learning in the process of schooling deaf people. It is in this amalgam of instituted truths that we problematized what has been produced about being deaf in the context of bilingual education, thus inferring as well as marking desires to be, learn and live.

Keywords: Deaf culture; learning; school experiences.

\section{RESUMEN}

Este artículo tiene como objetivo comprender la articulación entre los conceptos de cultura y aprendizaje como una condición de posibilidad de pensar acerca de la producción del sujeto sordo en el entorno de la escuela contemporánea. Para hacer frente a tal problema, el análisis realizado se basará en datos de una investigación realizada en 13 escuelas específicas de sordos en Rio Grande do Sul. De este proyecto analítico, que pone en funcionamiento dos posibles conceptos-herramienta - subjetivación y dispositivo pedagógico -seleccionamos 20 entrevistas con estudiantes sordos y 4 entrevistas con profesores, de un universo de 156 sujetos. Con base en las narrativas, consideramos las singularidades discursivas y las recurrencias que se extienden a las nociones de cultura y aprendizaje en la escolarización de las personas sordas. Acerca de esta amalgama de verdades instituidas es que problematizamos lo que se ha producido sobre el ser sordo en el contexto de la educación bilingüe, infiriendo e imprimiendo deseos de ser, aprender y vivir.

Palabras clave: Cultura sorda; aprendizaje; experiencias de la escuela.

\section{Introdução}

A proposição deste artigo insere-se no campo da educação de surdos, em uma tentativa de compreender a articulação entre os conceitos de cultura e de aprendizagem como condição de possibilidade para pensar a produção do sujeito surdo no cenário da escola contemporânea.

Para este exercício analítico, a centralidade estará na contingência da educação bilíngue de surdos e trará dois elementos norteadores: primeiro, os dados do projeto de pesquisa "Produções culturais surdas no contexto da educação bilíngue" desenvolvido por três universidades federais do Rio Grande do Sul, do qual somos participantes; segundo, nossas problematizações da educação de surdos, uma vez que somos profissionais e pesquisadoras que atuam na área.

No cotidiano acadêmico do Ensino Superior, em que atuamos como docentes na formação de futuros professores, observamos que as discussões e pesquisas tendem a posicionar a educação bilíngue para surdos com ênfase nos aspectos linguísticos, por vezes, sem tensionar o protagonista desta língua: o sujeito surdo. Por ser tida como uma 
opção salvacionista na educação de surdos, muitas vezes, a perspectiva centrada única e exclusivamente no uso da língua de sinais nos processos de educação dos sujeitos surdos engessa outros saberes e articulações.

Nesse território educativo, surgem inúmeras possibilidades de pensar sobre o fazer pedagógico em um contexto que chamamos de bilíngue. A partir dessas formas possíveis de narrar o ser surdo, trazemos para a discussão a educação bilíngue por entendermos a força discursiva de tal enunciado na educação de surdos. Como professoras e pesquisadoras na área, vimos emergir o conceito de educação bilíngue - e, de certa forma, ajudamos a fomentá-lo, seja pelos estudos na área da educação de surdos, seja por meio da luta em busca do reconhecimento oficial da língua brasileira de sinais no país como primeira língua das comunidades surdas, seja, ainda, pelos engajamentos políticos e em grupos de estudos que promovem a discussão do sujeito surdo pelo viés socioantropológico, e não pelo olhar clínico.

Nesse sentido, esses movimentos de luta e conquista no campo educacional e social, com o objetivo de mostrar a educação bilíngue como a educação que contempla de maneira mais adequada as especificidades linguísticas e culturais dos surdos, são discussões empreendidas com mais recorrência. Vale lembrar que, ao falarmos em bilinguismo na educação de surdos, considera-se a língua brasileira de sinais como primeira língua, e a língua portuguesa na modalidade escrita é vista como segunda língua. Contudo, neste trabalho, pretendemos lançar o olhar além, ou seja, entendendo a educação bilíngue como um dispositivo pedagógico que aciona práticas de subjetivação.

Para isso, assentaremos nossa discussão sobre dois eixos centrais que elegemos para pensar no contexto da educação bilíngue: aprendizagem [para a vida] e cultura [surda], tecendo arranjos e conexões que possibilitem compreender de que forma essa modalidade de educação vem produzindo modos de ser surdo na contemporaneidade. Assim, ao problematizarmos aprendizagem e cultura, compreendemos que ambas engendram práticas que produzem efeitos no contexto escolar, atuando nos modos de subjetivação dos sujeitos surdos.

Com esse entendimento, a análise aqui empreendida tomará como base os dados de uma pesquisa realizada em 13 escolas específicas de surdos do Rio Grande do Sul, em que o objetivo foi analisar a circulação e o consumo de artefatos culturais em contextos da educação bilíngue para surdos nos espaços da educação básica. Tal pesquisa compreendeu três fontes de materialidade analítica, sendo elas: documentos oficiais da 
http://dx.doi.org/10.5902/1984686X41272

escola, observações do cotidiano escolar e entrevistas semiestruturadas. Contudo, para este artigo, optamos por fazer um recorte do estudo e utilizar apenas as entrevistas como material de análise.

Com base nessas informações, a partir do relatório do projeto "Produções culturais surdas no contexto da educação bilíngue" da referida pesquisa, interessou-nos tratar da constituição do sujeito surdo, por entendermos que a educação bilíngue está pautada em um campo de saber que é a educação, a qual, por sua vez, está atrelada a este modo de vida contemporâneo, em que somos interpelados e conduzidos, ininterruptamente, a aprender sempre e aprender tudo. Este é um tempo de aprendizagem acelerada, em que um estilo de vida mais fluido, orgânico e mutável é produzido; de viver rápido, de controlar o tempo; de investimentos nas habilidades e competências profissionais; do saber além das disciplinas curriculares e dos conteúdos programáticos. O contemporâneo interpela-nos, conduzindo-nos à aprendizagem para a vida, ou melhor, ao longo dela.

Esses modos de vida contemporâneos são potencializados quando a identidade cultural de seus partícipes é significada e produzida nesse contexto. Compreender a comunidade surda como um dos grupos que compartilham modos de vida chama-nos a pensar a identidade cultural na pós-modernidade. Seja pela língua, pela experiência de ser surdo, pela constituição dos saberes perpassados pela visualidade ou pelo sentimento de pertencimento cultural, a comunidade surda espalhada pelo mundo apresenta similaridades.

Sendo assim, a partir dessas experiências compartilhadas, a emergência das políticas na educação de surdos e o movimento da comunidade surda são enunciados do grande discurso da educação bilíngue e fomentam ações que a localizam como a mais verdadeira ou propícia para a educação.

Como a educação bilíngue vem se constituindo como um potente dispositivo pedagógico no campo da educação das pessoas surdas, acreditamos ser importante enunciar alguns investimentos empreendidos nos últimos anos que viabilizaram atender a essa modalidade educacional e qualificá-la, como, por exemplo, a criação do primeiro curso de graduação de Licenciatura em Letras/Libras em 2006. Sob a responsabilidade da Universidade Federal de Santa Catarina (UFSC) ${ }^{1}$ e em parceria com diferentes instituições brasileiras, teve como objetivo formar professores e intérpretes para atuar nesse cenário escolar bilíngue para surdos. Também podemos citar o Prolibras², que é o Programa Nacional para a Certificação de Proficiência no Uso e Ensino da Língua Brasileira de Sinais 
e para a Certificação de Proficiência em Tradução e Interpretação da Libras/Língua Portuguesa, voltado a certificar, emergencialmente, profissionais que atuam na docência e interpretação nas duas línguas envolvidas na educação bilíngue.

Ainda como ação que se configura em investimentos para atender à formação de professores e gestores para atuarem na educação de surdos em um contexto bilíngue, temos o curso de Pedagogia Bilíngue oferecido pelo Instituto Nacional de Educação de Surdos (INES) ${ }^{3}$, com início em março de 2006 Segundo o Projeto Pedagógico do Curso, o objetivo é:

Formar pedagogas e pedagogos, surdos e ouvintes, em uma perspectiva bilíngue (Libras/Língua Portuguesa) e intercultural, para atuar na área da docência (educação infantil e anos iniciais do Ensino Fundamental), na gestão educacional e na educação em espaços não escolares (PPC, 2017, p. 26).

Considerando tanto esse cenário produtivo em que emerge a educação bilíngue, quanto as inúmeras práticas e ações que se estabelecem para dar-lhe ênfase e visibilidade, vale salientar também o investimento na ordem das produções de materiais didáticopedagógicos e as publicações teóricas sobre a temática bilíngue. Entendemos que tais produções são constituidoras de saberes sobre a educação de surdos e, principalmente, em relação ao que compreendemos e consideramos como educação bilíngue para surdos na contemporaneidade.

Nessas incursões acadêmicas, observamos que, ao mesmo tempo que há uma difusão e um alargamento das discussões sobre educação bilíngue no país, acontece o fechamento de muitas escolas de surdos, diminuindo significativamente o número de matrículas de alunos surdos nesses espaços. Inclusive, esse dado estatístico pode ser evidenciado a partir do relatório da pesquisa mencionado anteriormente, em que se nota esse decréscimo, como mostra o quadro abaixo:

Quadro 1 - Gráfico com a matrícula de alunos surdos no período de 2011-2016

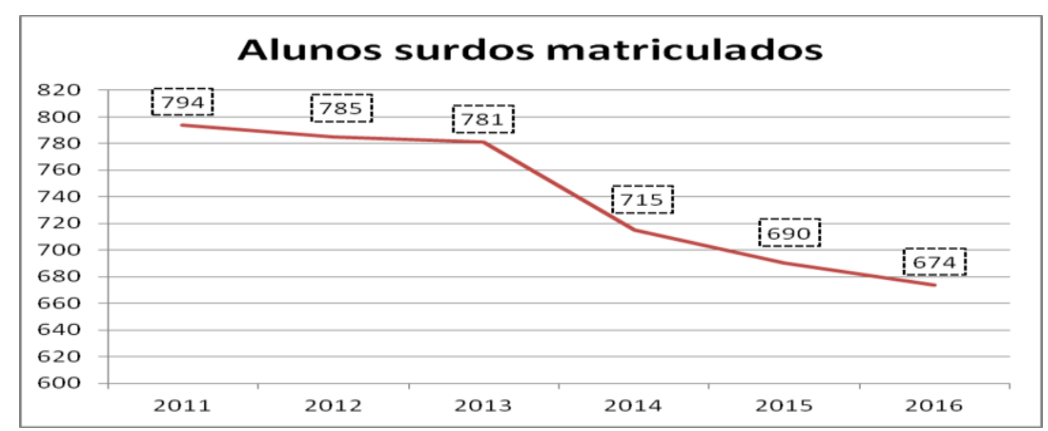

Fonte: Relatório do projeto (2017). 
http://dx.doi.org/10.5902/1984686X41272

Assim, tendo em vista esse contexto educacional bilíngue de surdos que vem se desenhando nos últimos anos, voltamos nosso olhar para a constituição desse sujeito surdo que se encontra atravessado pelas questões culturais e de aprendizagem (não apenas de conteúdo, mas aqui tratada como uma aprendizagem para a vida) como possibilidade de entender os modos de vida surdo.

\section{Percurso investigativo: problemáticas e metodologia}

Todo processo de pesquisa envolve uma sistematização, esboço de linhas e trajetórias de ação, bem como uma densa incursão no campo de pesquisa para que os estudos analíticos efetivem-se na escrita. Nesta seção, apresenta-se o caminho metodológico percorrido, salientando-se que o corpus analítico deste estudo será composto de parte dos dados disponíveis no projeto de pesquisa desenvolvido pelo Grupo Interinstitucional de Pesquisa em Educação de Surdos (Gipes) do qual participamos.

Entre os documentos oficiais manuseados nas escolas investigadas, as observações realizadas nesses espaços e as entrevistas semiestruturadas com professores e alunos, optamos por fazer um recorte e analisar apenas as entrevistas, por entendermos que nos dão condições de possibilidade para atender ao objetivo deste trabalho, que se propõe a compreender de que maneira a educação bilíngue engendra modos de ser surdo na contemporaneidade. Para potencializar essa problematização, usamos os elementos cultura (surda) e aprendizagem (para a vida) para pensar sobre a constituição do sujeito surdo, em um empreendimento analítico que coloca em operação dois possíveis conceitosferramenta: subjetivação e dispositivo pedagógico.

A seguir, debruçamo-nos sobre algumas informações necessárias sobre o projeto de pesquisa tomado como fonte empírica para o desenvolvimento deste artigo.

\section{Contextualização do projeto}

O referido projeto de pesquisa está sendo desenvolvido por pesquisadoras de três universidades federais do Rio Grande do Sul em 13 escolas específicas de surdos. Em 2014, iniciaram as atividades de mapeamento das instituições a serem pesquisadas, porém, apenas em 2017 é que foram realizadas as entrevistas para a coleta de dados, as quais continuam sendo analisadas, juntamente com os documentos da escola e o diário de campo. O objetivo principal do referido projeto é analisar a circulação e o consumo de 
artefatos culturais em contextos da educação bilíngue para surdos nos espaços da educação básica. Os objetivos específicos são os seguintes: (a) Problematizar as propostas de políticas educacionais do Ministério da Educação com ênfase na educação escolar bilíngue para surdos; (b) Analisar e entender as formas de apropriação da cultura surda no currículo escolar em escolas de educação básica; (c) Investigar a circulação e o consumo de artefatos culturais da cultura surda em práticas educacionais; (d) Identificar e analisar a produção, a circulação e o consumo de materiais literários utilizados em propostas pedagógicas na educação escolar bilíngue.

Para a execução da pesquisa, foram cumpridas três etapas: 1a Etapa Sistematização e análise dos dados produzidos nas pesquisas, Educação de surdos no Estado do RS e Produção, circulação e consumo da cultura surda brasileira. $2^{\mathrm{a}}$ etapa - A circulação e consumo dos artefatos culturais surdos no cotidiano escolar. $3^{\mathrm{a}}$ Etapa - Efeitos das recorrências do cotidiano escolar no contexto da educação bilíngue e possibilidades da construção de políticas curriculares bilíngues para surdos em uma perspectiva intercultural.

As escolas selecionadas foram distribuídas entre quatro escolas na capital, quatro escolas da região metropolitana de Porto Alegre e cinco escolas do interior do estado, sendo elas de diferentes esferas: particular (quatro), pública estadual (quatro) e pública municipal (cinco), como mostram os quadros abaixo:

Quadro 2 - Esferas Educacionais

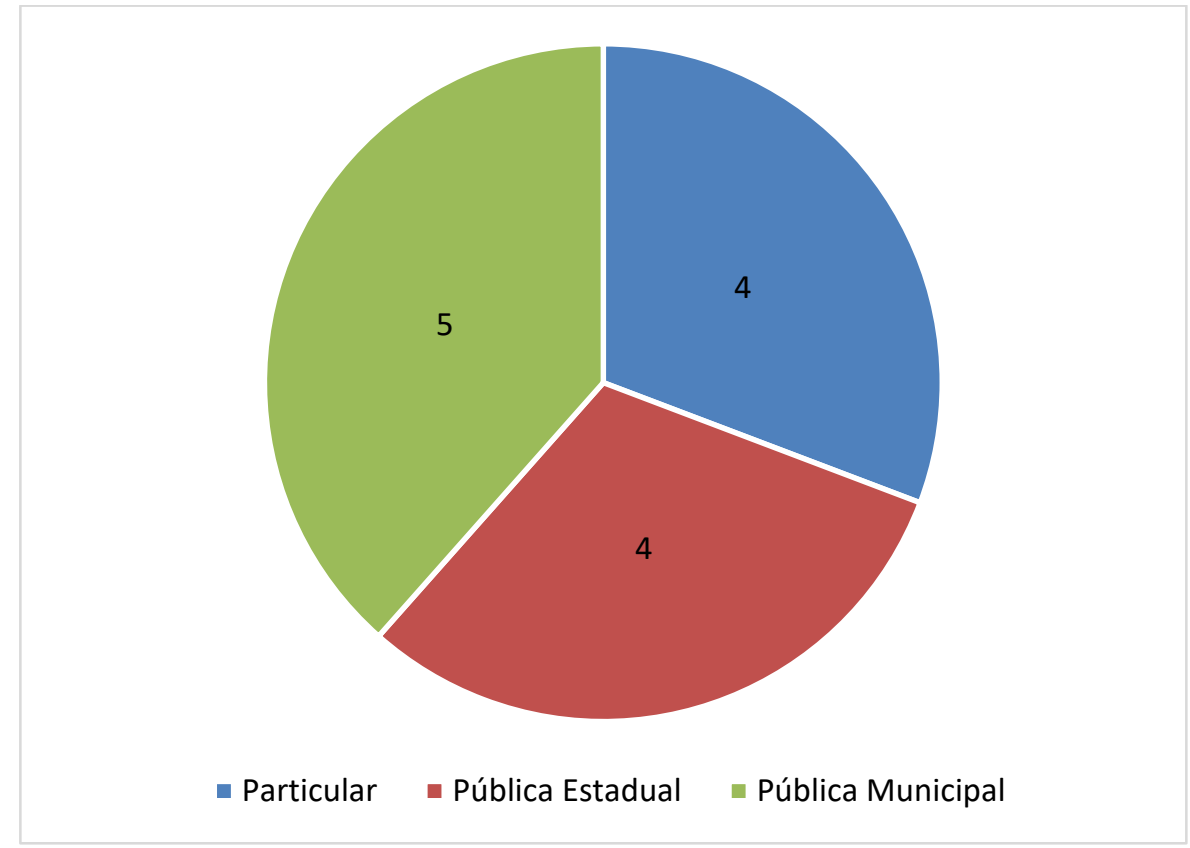

Fonte: Relatório do projeto (2017). 
Quadro 3 - Regiões das Escolas

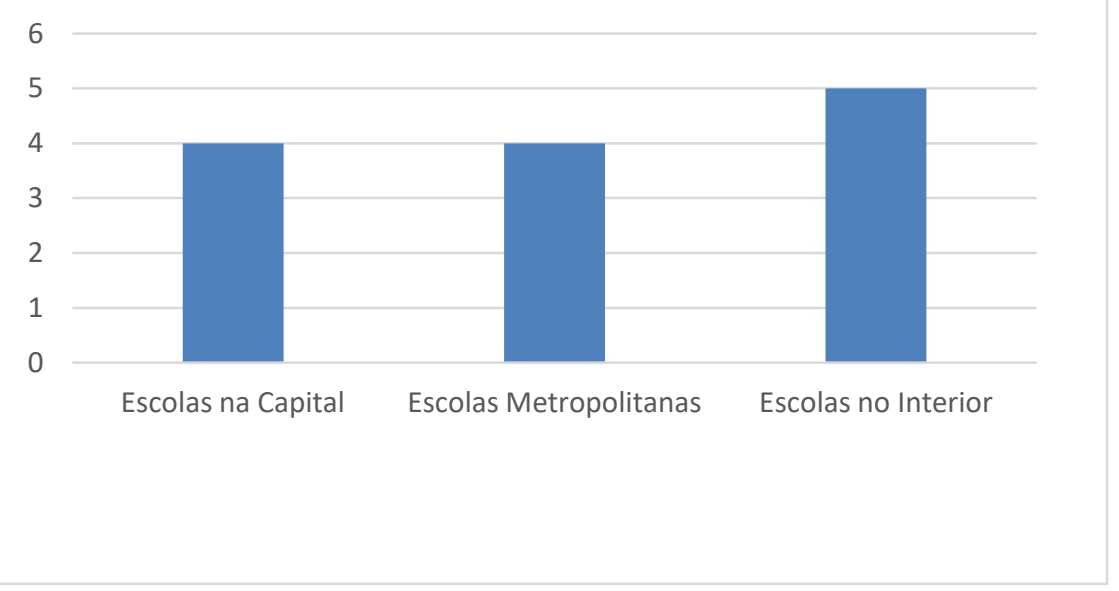

Fonte: Relatório do projeto (2017).

Como a materialidade de análise neste artigo está centrada nas entrevistas com os professores e alunos realizadas no projeto, daremos mais visibilidade a elas neste momento. Foram 130 alunos e 26 professores entrevistados, totalizando 156 sujeitos de pesquisa ${ }^{4}$.

Para fins de encaminhamentos metodológicos, as narrativas oriundas das entrevistas são alojadas em uma ordem discursiva, no sentido de que são elementos de produção de subjetividades surdas. Desse universo de 156 entrevistas, selecionamos 20 direcionadas aos alunos surdos e quatro destinadas aos professores, realizadas em Libras, interpretadas para a língua portuguesa na modalidade oral e depois transcritas para a modalidade escrita. A partir desses textos que compõem as narrativas, focalizamos as singularidades e recorrências discursivas que tangenciam a cultura e aprendizagem, a fim de constituir uma análise do discurso.

A seleção desse número de entrevistas para empreender esta análise deu-se por dois motivos: primeiro, porque neste momento não conseguiríamos dar conta de toda a materialidade do projeto na produção deste artigo; segundo, elegemos apenas duas das 13 escolas pesquisadas porque nelas acompanhamos todo o percurso investigativo, desde a visita a cada escola e realização das entrevistas até sua interpretação e transcrição.

A partir das entrevistas, foi possível construir um conjunto consistente de narrativas surdas e ouvintes, de professores e alunos envolvidos na educação de surdos, com singularidades e recorrências quanto aos elementos da cultura e aprendizagem no contexto da educação bilíngue. 
http://dx.doi.org/10.5902/1984686X41272

Nesse sentido, percebemos que a funcionalidade conceitual de cultura e aprendizagem é significada na escola. Com isso, neste trabalho, entendemos que essa enunciação no cotidiano dos alunos e professores, quando entendida como um saber legítimo, produz também um saber científico. A fala dos alunos e professores não é um mero palavrório e vai, paulatinamente, criando formas de participação desses surdos na sociedade. Esses saberes locais, singulares, são muitas vezes desvalidados por um conhecimento erudito, exato e com suporte institucional fundado em um sistema de edições e bibliotecas.

Em relação a esses saberes singulares, Foucault (1999, p. 15) indaga: "quais tipos de saber vocês querem desqualificar no momento em que vocês dizem ser esse saber uma ciência?"'. Ele também traz questionamentos acerca dos saberes dos sujeitos que os promovem, como: "qual sujeito falante, qual sujeito discorrente, qual sujeito de experiência e de saber vocês querem minimizar quando dizem: 'eu, que faço esse discurso científico e sou cientista?" (FOUCAULT, 1999, p.15). Esses saberes sujeitados estão sendo negociados a todo momento e em movimento diário no contexto escolar. Para Gadelha (2009, p. 24):

[...] com o auxílio de uma crítica erudita, a qual os ajudou a escapar aos mecanismos que buscavam filtrá-los, classificá-los, hierarquizá-los e ordenálos, os saberes sujeitados concorreram, a um só tempo, não só para a crítica ao poder, mas tornaram-se eles mesmos o móvel que tornou possível essa crítica.

Esses saberes não estão de forma isolada ou materializada por uma transcrição das entrevistas, mas levam-nos a entender que elas produzem significações e práticas que subjetivam o ser-surdo.

\section{Cultura, aprendizagem e educação bilíngue: articulações e efeitos nos modos de ser sujeito/aluno surdo}

Levando em conta que nossa vontade de potência está alojada na possibilidade de compreender a constituição do sujeito surdo no contexto da escola contemporânea com foco no caráter relacional entre cultura e aprendizagem, assumimos como centrais as narrativas dos sujeitos da pesquisa. Dessa forma, a linguagem toma a função de produtora de significados, uma vez que "o sujeito é um efeito das linguagens, dos discursos, dos textos, das representações, das enunciações, dos modos de subjetivação, dos modos de endereçamentos, das relações de poder-saber" (PARAíSO, 2014, p. 29). 
http://dx.doi.org/10.5902/1984686X41272

Seguindo esse conceito de linguagem, em que nomeamos e registramos objetos, práticas e sujeitos, dando-Ihes uma classificação, um ordenamento, um lugar de in/exclusão, trazemos a fala de uma professora ouvinte entrevistada que trabalha no Ensino Médio de uma das escolas de surdos investigadas e que atualmente ministra as disciplinas de História e Filosofia. Ao perguntarmos sobre o que considerava importante em uma escola de surdos (e se sua escola já tinha e/ou o que ainda faltava), ela disse:

Contemplar as necessidades não da comunidade surda, as necessidades intrínsecas da cultura surda. A escola de surdos tem que ter o entendimento das especificidades desta cultura e contemplar isso e a partir disso desenvolver seu currículo, desenvolver suas atividades pedagógicas, sempre nesse contexto. A questão linguística, sim, e as outras questões que pontuam o cotidiano de um surdo, e a cultura surda está presente em praticamente todas as ações ${ }^{5}$. (Professora ouvinte ${ }^{6}$ )

Nesse trecho, podemos destacar uma produção de sentidos em relação à educação de surdos que vislumbra também as questões de aprendizagem, tendo como fio condutor os elementos culturais surdos. A entrevistada sinaliza que a escola necessita considerar as especificidades surdas do currículo nas práticas pedagógicas, dando ênfase à língua de sinais. Pode-se depreender daí que estão presentes modos de produzir o que seria a educação de surdos e o aluno surdo, balizados por um ideal de normalidade surda que se deseja: um surdo usuário fluente da língua de sinais que vive a cultura surda.

Corroborando a premissa de que a escola de surdos deve contemplar tais elementos na educação de surdos, segundo a narrativa de dois alunos entrevistados, a escola ocupa esse lugar onde o ambiente linguístico e cultural é favorável para aprender e conviver com os pares. Segundo uma aluna surda do $2^{\circ}$ ano do Ensino Médio (17 anos):

Aqui tem tudo. Aqui tem língua de sinais... Tem tudo... Aqui é mais ou menos perfeito. É bilíngue, a única escola bilíngue. Poderia ter mais ensino de línguas, o que tornaria mais fácil.

Para um aluno surdo do 8ำ ano do Ensino Fundamental (15 anos):

A escola de surdos deve ter a língua de sinais, uma comunicação eficiente e facilitada, muitas trocas, a questão do orgulho surdo, de mostrar a surdez.

Ao dizermos o que a escola é ou não é, o que significa na vida dos que ali estão (surdos e ouvintes) ou o que se espera dela e da educação de surdos de modo geral, estamos construindo verdades sobre essa determinada realidade, ao mesmo tempo que nos constituímos sujeitos nela. Para Andrade (2014, p. 175), "tais experiências constituemnos e são produzidas e mediadas no interior de determinados espaços como a escola ou 
http://dx.doi.org/10.5902/1984686X41272

os espaços que remetem às experimentações nela conhecidas ou, ainda, no interior de determinadas práticas sociais".

Desse modo, a partir das narrativas que posicionam a língua de sinais e a cultura surda nas práticas escolares como mobilizadores importantes para a aprendizagem e 0 sucesso escolar dos alunos surdos, destacamos um deslocamento de ênfase no que se refere às questões de aprendizagem em outros dois momentos da fala de uma professora ouvinte. Podemos evidenciar, nesse caso, que a aprendizagem, na escola de surdos, vai além do compartilhamento da língua e da cultura.

Bom... A escola trabalha as disciplinas todas, os seus conteúdos... A formação em si está sempre no sentido de estimulá-lo para o mundo lá fora. Eles saem daqui concluintes de Ensino Médio, alunos que prestam vestibular, prestam o Enem. A escola também tem outro trabalho adicional, que é um apoio ao mercado de trabalho, currículo e tudo mais que aparece.

Eu sempre reforço para eles o seguinte: o que vai acontecer lá fora? Aqui, nas nossas quatro paredes, na escola especial, na escola onde eles são contemplados com tudo aquilo que eles precisam, mas essa escola está realmente preparando eles para o mundo lá fora?! O mundo lá fora é ouvinte e inclusivo... Então, a questão do mundo lá fora é: como vocês vão se virar? Alguns se viram muito bem; alguns são muito estimulados; outros não... Um tem que estimular o outro, essa ênfase a gente dá.

Salientamos nos excertos algumas expressões - por exemplo, mundo lá fora, formação, mercado de trabalho e tem que estimular o outro - como alavancas para pensar nos modos como nos constituímos sujeitos na contemporaneidade, a qual não se restringe ao sujeito ouvinte ou ao sujeito surdo, mas enreda todos. Percebe-se a produção de um capital humano ${ }^{7}$, um conjunto de habilidades, capacidades e destrezas desenvolvidas e acumuladas pelo sujeito, em um imperativo permanente de investir em si mesmo (GADELHA, 2009).

O mundo lá fora, ao qual a professora se refere, já não se encontra lá fora, já não é mais externo ao sujeito, uma vez que aquilo que parecia estar fora - os desejos que nascem de um possível mundo ouvinte - se torna o desejo do surdo também e de sua família, de seus professores e de toda a escola. O tem que estimular o outro está na esteira do conduzir a si mesmo e conduzir o outro a aprender. Afinal, a aprendizagem (para a vida) apresentase como a saída, ou melhor, é condição de possibilidade para a entrada nesse outro mundo (lá fora), que significa a formação, o vestibular a prestar, o curso a fazer, o trabalho a conseguir, o futuro próspero a alcançar. Entende-se que os limites entre o que se aprende e o que se ensina na escola já não podem ser rigorosamente demarcados. O papel da escola nesse cenário extrapola o ensino dos conteúdos curriculares, assim como, para o 
http://dx.doi.org/10.5902/1984686X41272

aluno, aprender ultrapassa os próprios muros da escola, pois a aprendizagem (para vida) toma proporções que avançam internamente no seu corpo e na sua alma, subjetivando-o a isso.

É nesse sentido que o conceito-ferramenta de subjetivação tem potência para pensarmos sobre os investimentos no âmbito pedagógico que têm visado à produção de sujeitos que desenvolvam suas habilidades e competências como princípio de mobilidade social. Dito de outro modo, é preciso compreender "as formas pelas quais as práticas vividas constituem e medeiam certas relações da pessoa consigo mesma" (PARAÍSO, 2014, p. 29) nas diferentes experiências e linguagens que conduzem e nomeiam o sujeito surdo hoje na escola.

Dando ênfase à condução das condutas dos sujeitos surdos quanto à aprendizagem (para a vida) no contexto contemporâneo, pontuamos a narrativa de um sujeito da pesquisa que foi mobilizado a pensar nas diferentes coisas que sua escola teria e dizer o que ajudaria a aprender melhor. Para este aluno surdo do $2^{\circ}$ ano do Ensino Médio (16 anos):

A possibilidade de aprender em Libras me ajuda. Em segundo lugar, as diferentes aulas, diferentes atividades que vão me ajudando, me dando aprendizagens para a vida.

Somando-se a isso, a narrativa de outro aluno pode ser compreendida a partir da noção de um governo de si e dos outros. Isso porque, na dinâmica em que as experiências culturais e educacionais estão alojadas em uma complexa rede de saber, poder e subjetivação, cada um conduz a si mesmo e conduz o outro, e aqui o registro está na matriz da aprendizagem. O aluno surdo do $2^{\circ}$ ano do Ensino Médio (17 anos) salienta:

Aquilo que mais ajuda a aprendizagem é quando tem ajuda, quando tem trocas, isso me ajuda a aprender melhor.

Podemos pensar, a partir de Biesta (2013), que nesse contexto emerge uma nova linguagem: a da responsabilidade na aprendizagem. Portanto, a aprendizagem como resposta àquilo que é diferente, àquilo que vem do outro, exige uma responsabilidade educacional, em que o professor precisa responder ao estranho (aluno, recém-chegado). Considerando esse outro recém-chegado de que fala Biesta (2013), o aluno surdo do $2^{\circ}$ ano do Ensino Médio (17 anos) afirma: "Eu acho que teria que melhorar as regras, talvez as regras para a aprendizagem, ver os diferentes jeitos que cada um aprende, porque cada pessoa tem um jeito". 
http://dx.doi.org/10.5902/1984686X41272

Essa narrativa pode ser tratada como um desejo produzido individualmente e, ao mesmo tempo, coletivamente pelo sujeito surdo ao responder sobre a escola de surdos ideal que ele imaginava. São sentidos produzidos que perpassam o desejo do aluno entrevistado e de uma comunidade surda em relação à aprendizagem no contexto da educação de surdos, tendo em vista que "o desejo é aquilo por que todos os indivíduos vão agir. (...) O desejo é a busca do interesse para o indivíduo" (FOUCAULT, 2008, p. 95).

No contexto contemporâneo, ainda sobre o sujeito da educação, há de se pensar no papel que a escola tem na produção do mesmo. Os binarismos que habitam o campo educacional implicam o cotidiano sistemático e pragmático da escola e estão imbricados nas práticas discursivas - como o currículo, a didática, o conteúdo e as relações sociais, que ocupam centralidade na condução das condutas dos sujeitos envolvidos. Em se tratando de espaços específicos de surdos, esse binarismo é apresentado com oposições identitárias, culturais e linguísticas.

Nesse sentido, o que ocorre é que o sujeito surdo é centrado na língua - Libras - e na cultura - cultura surda -, verdades que supõem uma essência subjacente. Nas oposições identitárias, geralmente um termo aparece como positivo, reprimindo o outro como raso e periférico. Portanto, ao falarmos em bilinguismo, falamos em duas línguas, mas que não estão na mesma esteira de significação.

O sujeito surdo na educação é visto como sujeito bilíngue, mas nas minudências e entranhas dessas línguas em contato é que se instauram situações conflitantes. O conceito cultura surda endossa esse discurso binário entre as duas línguas e engendra práticas que produzem efeitos no contexto escolar, ganhando força ao atuarem sobre os processos de subjetivação dos sujeitos surdos, pois constituem uma gama de significados que produzem verdades sobre si eles.

A cultura tem infinitas atribuições nos contextos políticos, educacionais e identitários. Ela é polissêmica, encontra elementos díspares, originários de diferentes visões do mundo e definições, mas, articulada à comunidade surda, ganha um caráter doutrinário e filosófico. A cultura surda, apesar de muitas vezes pedagogizada na escola, carrega também o caráter de experiência e pode ser percebida na narrativa de um dos sujeitos da pesquisa ao narrar o ambiente cultural surdo favorável ao aprendizado. Para o aluno surdo do $2^{\circ}$ ano do Ensino Médio (16 anos): 
http://dx.doi.org/10.5902/1984686X41272

Eu me sinto muito bem aqui, eu desejo mesmo estar aqui. Se estivesse em outra escola, independentemente da escola que fosse, mas que tivesse ouvintes, eu não ia me sentir tão confortável, nem me sentir tão familiarizado, principalmente por essa questão do aprendizado e da visualidade. No caso do professor ouvinte, uma prática comum em uma sala de aula é o professor chamar o aluno pelo nome, e, se eu, por exemplo, estivesse de cabeça baixa, escrevendo, eu não iria perceber. Isso acontece porque o surdo usa a questão do olhar, do ver, e não do ouvir (...) Aqui, sim, pela própria questão da disposição das cadeiras, eu posso ver os meus colegas e professores sinalizando. Por isso, eu quero me manter nessa escola, que é um lugar em que realmente me sinto muito bem.

Ainda sobre o fator cultural atrelado à questão linguística, vejamos a fala de um professor surdo ao descrever o que faz da sua escola uma escola de surdos, ou uma escola bilíngue. Para este professor:

Porque aqui a primeira língua é a Libras, e a segunda língua é a língua portuguesa. É diferente da escola de ouvintes, onde a primeira língua é a língua portuguesa e a cultura é baseada na cultura ouvinte, na cultura da oralidade. Então, aqui temos uma característica própria da escola de surdos, que é visual e tem um currículo próprio, específico.

A relação entre as esferas cultural, educacional e de constituição do sujeito não é nova, mas entender nesse processo como a proliferação do discurso sobre cultura surda conduz à subjetivação desse sujeito e, muitas vezes, produz um determinismo na forma como ele relaciona-se com o conhecimento é fundamental. O discurso sobre o bilinguismo na educação de surdos é naturalizado, e a maneira como emerge a potente cultura surda como genuína nos processos de aprendizagem é efervescente em qualquer espaço acadêmico ou de saber científico sobre o tema.

Diante desse cenário, é impossível dissociar língua e cultura nos modos de vida do sujeito surdo, principalmente na escola, que é lócus privilegiado de produção de sentidos. Nas narrativas, fica evidente não só uma celebração da aquisição da Libras como marco na constituição identitária, como também uma repulsa aos atravessamentos binários com a língua oral na modalidade escrita. Destacamos algumas recorrências referentes à importância da Libras quando os sujeitos foram questionados: por que você estuda nesta escola, e não em outra?

Segundo o relato de uma aluna surda do $2^{\circ}$ ano do Ensino Médio (17 anos):

Eu quis estudar na $X$ porque 0 aprendizado é muito bom, a gente se desenvolve bastante, o ensino é através da língua de sinais, e através dela se ensinam várias coisas, outras escolas. Na escola de ouvintes, eu tive muita dificuldade, é muito ruim, principalmente em referência à comunicação. Também me sentia muito menosprezada, não me sentia segura. Os professores tentavam se comunicar comigo, e eu nunca consegui estabelecer 
http://dx.doi.org/10.5902/1984686X41272

uma comunicação com eles. Então, prefiro X por o aprendizado ser na língua de sinais.

Já outro aluno surdo do $2^{\circ}$ ano do Ensino Médio (17 anos) destaca:

Porque aqui eu tenho muita comunicação, tenho amigos e consigo conversar.

E ainda, segundo outro aluno surdo do $8^{\circ}$ ano do Ensino Fundamental (13 anos):

Porque é bom, é importante estudar aqui, eu gosto (...) Na escola inclusiva, é bem difícil. Aqui tem a língua de sinais, então, é melhor.

O caráter bilíngue não é equilibrado, não está na mesma esteira de significação e experiência; portanto, as forças homogeneizantes de cultura tornam-se elementos a serem problematizados, haja vista que, para a afirmação do eu, o apagamento do outro intensificase, incluindo seus sujeitos, sua cultura e sua língua em uma relação de assimetria.

Em uma das narrativas analisadas, podemos perceber o caráter social atribuído às línguas em contato. Vejamos as palavras de um dos sujeitos da pesquisa no que se refere à noção de pertencimento à escola, apontando um sentimento de inferioridade quando utiliza a língua oral ao relatar momentos marcantes em sua trajetória escolar. Quanto a isso, o aluno surdo do $3^{\circ}$ ano do Ensino Médio (56 anos):

Aqui no X, com os colegas, eu tenho vontade de me profissionalizar (...) Mas eu não gostei e não gosto da oralização porque eu não entendo. Com a oralização, eu não entendo nada, eu me sinto bobo

Nesses regimes de enunciabilidade, em que os mecanismos discursivos narram e interpretam, é que a estrutura da memória de si é constituída. Larrosa (1994) pontua que as máquinas discursivas determinam uma espécie de topologia da subjetividade, ou seja, aquilo que a pessoa pode ver em si mesma e como, ao nomeá-lo, pode traçar seus limites e seus contornos. $\mathrm{O}$ autor compreende os dispositivos pedagógicos como constitutivos da subjetividade que adota um ponto de vista pragmático sobre a experiência de si.

Sendo assim, podemos pensar nos inúmeros atravessamentos discursivos que circulam no interior das escolas e que operam na construção identitária de seus alunos. Muitos são os depoimentos de alunos surdos que significam a escola como espaço acolhedor e de estar com seus pares. Esses depoimentos enunciam a preferência desse espaço, atribuindo-Ihe também fator comunitário, assim agregando mais sentido para as questões de aprendizagem (para a vida). A seguir, dois excertos das narrativas em resposta à pergunta: o que nesta escola te ajuda a aprender melhor?

De acordo com o aluno surdo do $2^{\circ}$ ano do Ensino Médio (42 anos): 
http://dx.doi.org/10.5902/1984686X41272

Na verdade, eu gosto muito da escola X. Aqui eu aprendo, tem professores e tem surdos, a gente se diverte, é bom e agradável.

Para o aluno surdo do $8^{\circ}$ ano do Ensino Fundamental (13 anos):

O que eu considero mais importante aqui na escola $X$ é o contato com os surdos e estar em comunidade. Com o grupo, eu me sinto muito bem.

O amparo comunitário perpassado pelo discurso cultural fornece seguridade. Porém, ao mesmo tempo, não podemos deixar de notar o caráter constitutivo e potente que agrega elementos que produzem esse sujeito surdo.

\section{Considerações finais}

Por fim, ao tomarmos a tríade cultura, aprendizagem e educação bilíngue como um tema para pensar os processos de subjetivação das pessoas surdas, colocamos no centro do debate outras possibilidades para pensar as experiências escolares dos alunos surdos. Para Veiga-neto (2004), é no decurso do trabalho que novas possibilidades podem abrirse, inclusive mais instigantes e muitas vezes impensadas, mas só se estivermos abertos ao novo, ao inusitado, e insatisfeitos com o que temos.

Considerando o conjunto de dados coletados, direcionamos nosso olhar para os saberes sujeitados da comunidade surda, que se configuram como forma de enunciação do discurso em defesa das escolas específicas de surdos. Sobre esse amálgama de verdades instituídas pelos surdos, que se dá nas miudezas das falas e conversas direcionadas pelas entrevistas, é que tensionamos o que vem sendo produzido sobre o ser surdo no contexto da educação bilíngue, inferindo e imprimindo desejos de ser, aprender e viver.

Pode-se pensar esse sujeito justamente como sujeito, ou seja, sujeitado a práticas e discursos da contemporaneidade. Biesta (2013) traz a educação dos recém-chegados como uma intervenção na vida de alguém motivada pela ideia de que tornará essa vida melhor, mais completa, harmoniosa ou até mesmo perfeita. A condução de vida gerenciada por esses atores do contexto escolar garante uma seguridade social, moldando e aprimorando as práticas de vida.

No paradoxo entre a disparidade e, ao mesmo tempo, a rigidez dos binarismos de língua e cultura nos territórios e práticas é que propomos estratégias de fuga para o essencialismo classificatório do sujeito surdo na educação. Já sabemos que a língua de sinais e a língua oral do país na modalidade escrita é o que baliza a educação bilíngue. 
http://dx.doi.org/10.5902/1984686X41272

Mas em que medida essas línguas são consumidas e significadas na escola? São elas articuladas aos processos culturais? Existe um sentimento de pertença às duas línguas e culturas? Que efeitos a relação cultura e aprendizagem produz nos modos de existência do sujeito surdo? Como os sujeitos surdos estão conduzindo a si mesmos e a outros surdos nesse contexto bilíngue? Essas, entre outras inquietações, talvez possam contribuir, em alguma medida, para pensarmos nas imbricações entre língua, cultura, aprendizagem e subjetivação e/ou modos de vida.

\section{Referências}

ANDRADE, Sandra dos Santos. A entrevista narrativa ressignificada nas pesquisas educacionais pós-estruturalistas. In: MEYER, Dagmar Estermann; PARAÍSO, Marlucy Alves (orgs.), Metodologias de pesquisas pós-críticas em Educação. Belo Horizonte, Mazza Edições, p. 173-194, 2014.

BIESTA, Gert. Para além da aprendizagem: educação democrática para um futuro humano. Belo Horizonte, Autêntica, 206 p., 2013.

COSTA, Sylvio de Souza Gadelha. Governamentalidade Neoliberal, Teoria do Capital Humano e Empreendedorismo. Educação \& Realidade, v. 34 (n. 2, mai/ago): p. 171-186, 2009.

FOUCAULT, Michel. Em defesa da sociedade: curso no Collège de France (1975-1976). Tradução de Maria Ermantina Galvão. São Paulo, Martins Fontes, 382 p., 1999.

FOUCAULT, Michel. Segurança, território e população: curso no Collège de France (1977-1978). São Paulo, Martins Fontes, 572 p., 2008.

GADELHA, Sylvio. Biopolítica, governamentalidade e educação: introdução e conexões, a partir de Michel Foucault. Belo Horizonte, Autêntica, 238 p., 2009.

INSTITUTO NACIONAL DE EDUCAÇÃO DE SURDOS (INES). Projeto Pedagógico do Curso de Licenciatura em Pedagogia. Disponível em: http://www.ines.gov.br/. Acesso em 21/03/2018, 2017.

LARROSA, Jorge. Tecnologias do eu e educação. In: SILVA, Tomaz Tadeu (org). 0 sujeito da Educação: estudos foucaultianos. Petrópolis, Vozes, p. 35-86, 1994.

MINISTÉRIO DA EDUCAÇÃO. Programa Nacional para a Certificação de Proficiência no Uso e Ensino da Língua Brasileira de Sinais - Libras e para a Certificação de Proficiência em Tradução e Interpretação da Libras/Língua Portuguesa. Disponível em: http://portal.mec.gov.br. Acesso em: 16/05/2018, 2011. 
http://dx.doi.org/10.5902/1984686X41272

PARAÍSO, Marlucy Alves. Metodologias de pesquisas pós-críticas em educação e currículo: trajetórias, pressupostos, procedimentos e estratégias analíticas. In: MEYER, Dagmar Estermann; PARAíSO, Marlucy Alves (orgs.). Metodologias de pesquisas póscríticas em Educação. Belo Horizonte, Mazza Edições, p. 23-45, 2014.

UNIVERSIDADE FEDERAL DE SANTA CATARINA. Curso de graduação de Licenciatura em Letras/Libras. Disponível em: http://libras.ufsc.br/. Acesso em: 16/05/2018, 2006.

VEIGA-NETO, Alfredo. Michel Foucault e os Estudos Culturais. In: COSTA; Marisa Vorraber; VEIGA-NETO, Alfredo (orgs). Estudos Culturais em educação: mídia, arquitetura, brinquedo, biologia, literatura e cinema. Porto Alegre, Editora UFRGS, p. 3769, 2004.

\section{Notas}

1 Em 2008, teve início o curso de graduação em Letras/Libras Bacharelado.

2 Exames realizados anualmente a partir de 2011, sob a responsabilidade do Instituto Nacional de Educação de Surdos (INES).

${ }^{3} \mathrm{O}$ curso é ofertado na sede do INES, em 11 instituições/institutos federais do Brasil e um estadual. No total, são 13 espaços para formação.

${ }^{4}$ Cabe salientar que as entrevistas, bem como as observações nas escolas, atenderam às exigências do Comitê de Ética.

${ }^{5}$ Formatação grafada em negrito para destacar trechos das narrativas dos sujeitos entrevistados.

${ }^{6}$ Os sujeitos não serão identificados, uma vez que fazem parte de um relatório que apresenta normas de sigilo. Nesse sentido, para fins de contextualização, apenas identificaremos se são professores ou alunos, e quando for aluno, a turma e a idade do entrevistado.

7 Uma discussão mais aprofundada da Teoria do Capital Humano, desenvolvida por Theodore Schultz (economista da Escola de Chicago), encontra-se no artigo Governamentalidade Neoliberal, Teoria do Capital Humano e Empreendedorismo, de Sylvio Gadelha Costa.

\section{Correspondência}

Márcia Lise Lunardi-Lazzarin - Universidade Federal de Santa Maria, Centro de Educação, Campus Universitário, Prédio 16, Camobi, Santa Maria, Rio Grande do Sul - Brasil. CEP: $97105-900$

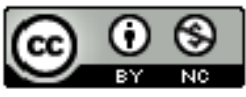

This work is licensed under a Creative Commons Attribution-NonCommercial 4.0 International (CC BY-NC 4.0) 